\title{
VALIDATION OF A MEASURE OF LEARNING AND PERFORMANCE GOAL ORIENTATIONS
}

\author{
TERESA DEBACKER ROEDEL \\ University of Oklahoma \\ GREGORY SCHRAW AND BARBARA S. PLAKE \\ University of Nebraska-Lincoln
}

\begin{abstract}
This study investigated the psychometric properties of an instrument (i.e., the Goals Inventory) that measured learning and performance goal orientations. Test-retest reliability estimates for the learning and performance goal scales were $r=.73$ and $r=.76$, respectively. Internal consistency estimates were assessed using Cronbach's alpha. These values were .80 and .75 , respectively. Convergent and divergent validity were evaluated by comparing the Goals Inventory to measures of test anxiety, hope, and attributions for success and failure. All the theoretically explicit predictions of Dweck and Leggett's model were supported. Suggestions are made for the use and interpretation of the Goals Inventory's two subscales and for future research.
\end{abstract}

A great deal of attention has been focused recently on Dweck and Leggett's (1988) social-cognitive theory of motivation. This theory postulates a causal relationship between a person's goal orientation and behavioral responses in academic settings. A learning orientation (i.e., a concern for personal improvement and mastery) leads to adaptive responses such as strategy shifting, increased effort, and persistence in the face of difficulty (Ames, 1992; Dweck \& Leggett, 1988; Elliott \& Dweck, 1988). A performance orientation (i.e., a concern for normatively high performance) leads to maladaptive behaviors such as self-aggrandizement, lack of persistence, and learned helplessness (Blumenfeld, 1992; Diener \& Dweck, 1978; Dweck, 1975; Meece, Blumenfeld, \& Hoyle, 1988).

Despite the theoretical and applied importance of these constructs, little effort has been made to develop or validate a standardized goal orientation 
inventory. One exception is a recent study by Miller, Behrens, Greene, and Newman (1993) that included learning and performance subscales as components of a larger instrument. However, even in this study, the psychometric adequacy of the learning and performance subscales was not evaluated other than through informal assessments of face validity.

In response to the theoretical importance of Dweck and Leggett's (1988) theory and the increase in research in this area over the past few years, the purpose of this study was to construct an inventory that was suitable for measuring learning and performance goals held by older students and to examine the psychometric properties of the inventory. Specifically, convergent and divergent validity were measured against a number of theoretically related measures: (a) Reactions to Tests (Sarason, 1984), which measured four dimensions of test-related anxiety; (b) the Hope Scale (Snyder et al., 1991), which measured two dimensions of hope as it relates to goal attainment-agency (the sense of being able to attain goals) and pathways (knowing how to successfully pursue goals); and (c) an attribution inventory, which measured endorsement of 12 different causes for academic success and failure.

Finally, four predictions were tested. First, the 25 -item Goals Inventory would yield two independent factors (i.e., learning and performance) as predicted by Dweck and Leggett (1988). Second, the learning factor would correlate negatively with the Reactions to Tests' four subscales (Sarason, 1984) whereas the performance factor would correlate positively. This prediction reflects the hypothesis that a performance orientation may increase an individual's stress and performance anxiety due to the possibility of failure. By contrast, a learning orientation may increase an individual's willingness to seek challenge, which, in turn, would lead to a negative correlation with adverse test reactions. Third, the learning factor would correlate positively with the Hope Inventory's (Snyder et al., 1991) two subscales whereas the performance factor would correlate negatively. This prediction is based on the assumption that individuals with learning orientations experience a greater sense of personal agency (i.e., feeling they can do something) and pathways (i.e., believing they know how to do it). Fourth, attributions for academic success and failure would correlate with the learning and performance factors in a manner analogous to that in Ames and Archer (1988), who reported that controllable variables (e.g., effort and strategies) correlated positively with the learning orientation whereas uncontrollable variables (e.g., luck and ability) correlated positively with the performance orientation. This pattern reflects the assumption that individuals with performance and learning orientations attribute success and failure to different causes. The former emphasize fixed, uncontrollable causes; the latter focus on changeable, controllable causes. 


\section{Method}

\section{Participants}

A total of 187 undergraduate students enrolled in an educational psychology course at a large midwestern university participated in this study for course credit. These were 71 males and 116 females. The majority of participants were White and came from middle-class backgrounds.

\section{Instruments}

Participants completed four questionnaires, the first of which was the focus of the study. The other measures were included for validation purposes.

Goals Inventory. The Goals Inventory consists of 25 items reflecting attitudes and behaviors that are associated with the learning and performance goal orientations. Students used a 5-point Likert-type scale to indicate how true each item was of themselves. This instrument was modeled on an earlier 48-item measure of goal orientation (Schraw \& Roedel, 1993). In the interest of parsimony, 23 items from the longer version were dropped for the present study on the basis of low factor loadings and/or item-to-total correlations.

Reactions to Tests. The 40-item Reactions to Tests (Sarason, 1984) measure of test anxiety includes four subscales (10 items each): (a) Tension, (b) Worry, (c) Test-Irrelevant Thinking, and (d) Bodily Symptoms. Students used a 4-point Likert-type scale to report how typical each behavior was of themselves. The reliability and validity estimates for this instrument have been reported by Sarason (1984). For the present sample, internal consistency coefficients obtained using Cronbach's alpha were as follows: Tension, $\alpha=$ .93; Worry, $\alpha=.89$, Test-Irrelevant Thinking, $\alpha=.91$; Bodily Symptoms, $\alpha=.86$.

The Hope Scale. The Hope Scale (Snyder et al., 1991) is a 12-item Likert-type instrument that measures two constructs related to hope: (a) Agency and (b) Pathways. The reliability and validity estimates for this instrument have been reported by Snyder et al. (1991). Internal consistency reliability estimates for the present sample using Cronbach's alpha were as follows: Agency, .65; Pathways, .67.

Attribution Inventory. The Attribution Inventory consisted of a list of 12 common attributions for success. Consistent with Weiner's (1985) discussion of dominant causal perceptions, these attributional statements included ref- 
erence to both internal and external locus of success and to stable/unstable and controllable/uncontrollable dichotomies in perceptions of causality. Students used a 5-point Likert-type scale to indicate the extent to which they agreed with each statement. To confirm our predictions concerning the relationship between students' attributions for success and their goal orientation, point-biserial correlation coefficients were used to assess the relationship between endorsement of each of the 12 attributional statements and both the learning and performance subscales of the Goals Inventory.

\section{Procedure}

Questionnaires were group administered. In each case, the order of administration was (a) Goals Inventory, (b) Reactions to Tests (Sarason, 1984), (c) Hope Scale (Snyder et al., 1991), and (d) Attribution Inventory. The session began with an explanation of the use of Likert-type scales and a brief introduction to each instrument in the packet. Students then worked at their own pace to complete the questionnaires. At the end of the session, students were debriefed and told to expect one more questionnaire to be distributed to them by their educational psychology course instructor in approximately 2 weeks. Students were not told that the purpose of the final instrument was to assess test-retest reliability or that they might recognize the final instrument.

After approximately 2 weeks, students received a second copy of the Goals Inventory with instructions to complete it within 24 hours and return it to their instructor or the researcher. Of 187 participants, 171 were included in test-retest analyses.

\section{Statistical Analysis}

Principal factor analysis of all items on the Goals Inventory was performed using a varimax rotation. Two factors were extracted on the basis of having eigenvalues greater than 1 . Items with loadings in excess of 3 on a factor were retained. Communality estimates (the squared multiple correlation with the factors) for the retained items ranged from .16 to .56 . Cronbach's alpha was used to measure the internal consistency of scales emerging from the factor analysis.

Pearson correlation coefficients were used to measure the relationship between (a) both the learning and performance subscales of the Goals Inventory and (b) each subscale of Reactions to Tests (Sarason, 1984) and each subscale of the Hope Scale (Snyder et al., 1991).

Point-biserial correlation coefficients were used to measure the relationship between (a) both the learning and performance subscales of the Goals Inventory and (b) each of the 12 attributional statements. 


\section{Results}

Factor analysis of the Goals Inventory revealed two uncorrelated factors that accounted for $64 \%$ of the total sample variation. The factors were identical to the learning and performance goals proposed by Dweck and Leggett (1988). Twelve items loaded on the learning factor $(\alpha=.80)$, which accounted for $39 \%$ of the total sample variance. Five items loaded on the performance subscale $(\alpha=.76)$, which accounted for $25 \%$ of the total sample variance (see Table 1). These findings closely matched those of Roedel and Schraw (1993) and Schraw and Roedel (1993).

A factor analysis of retest scores was identical to the original in terms of factor loadings and variance accounted for. Test-retest correlations reached $r=.73$ and $r=.76$ for the learning and performance subscales, respectively. The magnitude of these correlations indicated that both scales were reliable over time to roughly the same extent as the instrument is reliable at a single point in time.

Correlations between the Goals Inventory and Reactions to Tests (Sarason, 1984) subscales confirmed the predictions. The performance subscale was correlated positively with each of the four Reactions to Tests subscales, whereas the learning subscale was correlated negatively with Tension, Worry, and Test-Irrelevant Thinking (see Table 2). This pattern indicates that high performance scores are associated with tension, worry, and general test anxiety, an outcome predicted by Dweck and Leggett (1988) given the tendency of performance-oriented individuals to focus on normatively high performance. By contrast, high learning scores were not associated with test anxiety, an outcome consistent with high concern for improvement but low concern for normatively high performance.

Correlations between the Goals Inventory and the Hope subscales (Snyder, 1991) matched the predictions with one exception. As expected, the learning orientation was correlated positively to pathways and agency, indicating that concern for improvement and personal mastery is associated with what Snyder et al. (1991) referred to as "the will (agency) and the ways (pathways)" (p. 570) (see Table 2). In addition, individuals with a performance orientation experience some limited sense of pathways even though they do not experience a sense of agency. This pattern of results suggests that these individuals may adopt maladaptive behaviors such as avoiding challenge not because they lack behavioral pathways but because they believe they cannot successfully negotiate these pathways.

Correlations between the subscales of the Goals Inventory and the 12 attributional statements closely matched the predictions set forth in this study and the findings reported by Ames and Archer (1988). One general difference is that the magnitudes of effect reported by Ames and Archer tended to be somewhat larger than those observed in the present investigation although 
Table 1

The Goals Inventory With Corresponding Factor Loadings

Learning Performance

\begin{tabular}{lll}
\hline L 1. I enjoy challenging school assignments. & .541 & .000 \\
L 3. I persevere even when I am frustrated by a task. & .489 & .000 \\
L 6. I try even harder after I fail at something. & .407 & .000 \\
L 7. I adapt well to challenging circumstances. & .412 & .000 \\
L 9. I work hard even when I don't like a class. & .553 & .000 \\
L 10. I am very determined to reach my goals. & .542 & .000 \\
L 11. Personal mastery of a subject is important to me. & .413 & .000 \\
L 12. I work very hard to improve myself. & .566 & .000 \\
L 16. I am naturally motivated to learn. & .642 & .000 \\
L 17. I prefer challenging tasks even if I don't do as well at them. & .612 & .000 \\
L 22. I feel most satisfied when I work hard to achieve something. & .413 & .000 \\
L 25. I give up too easily when faced with a difficult task.* & -.455 & .000 \\
P 2. It is important for me to get better grades than my classmates. & .321 & .575 \\
P 13. I like others to think I know a lot. & .000 & .591 \\
P 14. It bothers me the whole day when I make a big mistake. & .000 & .523 \\
P 15. I feel angry when I do not do as well as others. & .000 & .746 \\
P 24. It is important to me to always do better than others. & .000 & .689 \\
F 4. Academic success is largely due to effort. & .254 & .000 \\
F 5. Sticking with a challenging task is rewarding. & .307 & .000 \\
F 8. I am willing to cheat to get a good grade.* & -.352 & .000 \\
F 18. Every student can learn to be a successful learner. & .000 & .000 \\
F 19. Learning can be judged best by the grade one gets. & .000 & .000 \\
F 20. My grades do not necessarily reflect how much I learn. & .000 & .000 \\
F 21. Mistakes are a healthy part of learning. & .000 & .000 \\
F 23. I would rather have people think I am lazy than stupid. & .000 & .287 \\
\hline
\end{tabular}

Note. $\mathrm{L}=$ Learning subscale $\mathrm{P}=$ Performance subscale $; \mathrm{F}=$ Filler items.

*Items to be reverse coded.

the direction of these differences was similar between studies. For example, strategy use was correlated positively with the learning orientation but was independent of the performance orientation (see Table 2). This finding indicates that individuals with a performance orientation see no relationship between classroom success and strategy use. In the present study, luck attributions were correlated negatively to the learning orientation, suggesting that these individuals are disinclined to attribute success to random causes.

\section{Discussion}

Several previous studies using the Goals Inventory have indicated the presence of a marginally interpretable third factor (i.e., an eigenvalue less than 1) labeled Persistence (Schraw \& Roedel, 1993). In these instances, items included on the persistence scale have split from items included on the mastery scale. A third interpretable factor was not detected in the present 
Table 2

Correlations Between the Goals Inventory Subscales and Other Measures

\begin{tabular}{lll}
\hline \hline & Learning & Performance \\
\hline Reactions to Tests & & \\
Tension & $-.15^{*}$ & $.35^{* * *}$ \\
Worry & $-.28^{* * *}$ & $.31^{* * *}$ \\
Test-Irrelevant Thinking & $-.36^{* * *}$ & $.24^{* *}$ \\
Bodily Symptoms & -.07 & $.34^{* * *}$ \\
Hope Subscales & & \\
Pathways & $.30^{* * *}$ & $.17^{*}$ \\
Agency & $.52^{* * *}$ & .00 \\
Attributions & & \\
Effort & $.16^{*}$ & .09 \\
Ability & .01 & .10 \\
Attitude & .08 & $.18^{*}$ \\
Strategy use & $.31^{* * *}$ & .06 \\
Luck & $-.23^{* *}$ & $.16^{*}$ \\
Teacher & -.02 & $.15^{*}$ \\
Textbook & .10 & -.00 \\
Background Knowledge & -.08 & .05 \\
Motivation & .04 & .08 \\
Task Difficulty & -.05 & $.16^{*}$ \\
Personal Interest & -.09 & $.17^{*}$ \\
Confidence & $.19^{*}$ & .14 \\
\hline
\end{tabular}

${ }^{*} p<.05 ;{ }^{* *} p<.01 ;{ }^{* * *} p<.001$.

study. However, it is recommended that users adopt one of two strategies when using the Goals Inventory. One is to use the factor structure shown in Table 1 without reanalysis. A second is to analyze data sets using a forced, two-factor solution. In several of the researchers' own data sets, this procedure yielded a factor structure identical to the one reported here even in cases where a marginal third factor was reported.

The present findings suggest that learning and performance goal orientations differ from one another in important ways. For example, scores on the learning orientation are associated with high self-agency and low test anxiety whereas the reverse is true of the performance orientation. Given these findings, it is tempting to conclude that learning and performance orientations are mutually exclusive endpoints of a single continuum. Such a conclusion is unwarranted, however, because studies consistently report statistical independence between the two (Ames \& Archer, 1988; Dweck \& Leggett, 1988; Roedel \& Schraw, 1993; Schraw \& Roedel, 1993).

Statistical independence has two important implications in this context. First, it implies that learning scores do not affect performance scores and vice versa. Some students may score high or low on both whereas others may score 
high on one dimension but low on the other. Second, users of the Goals Inventory should bear in mind that a student's goal orientation is a multirather than unidimensional phenomenon. Given the multidimensional nature of the two orientations, a large number of "goal configurations" are possible.

Presently, it is unknown whether some configurations predispose students to greater academic success or greater self-esteem. One possibility is that individuals scoring high on both dimensions may be more apt to succeed than are others. Such individuals would be simultaneously concerned with improving competence (i.e., developing new skills and knowledge) and performing at normatively high standards. Future research should be directed at investigating the implications of multidimensional goal orientations and the possible compensatory effect one orientation may have on another.

\section{Conclusion}

The purpose of this research was to investigate the psychometric properties of an inventory that measured the learning and performance goal orientations described by Dweck and Leggett (1988). The 25-item Goals Inventory was developed for this study and was shown to be internally consistent and reliable over time. Comparisons to measures of hope of goal attainment and multiple measures of test anxiety suggested that the Goals Inventory has a high degree of convergent and divergent validity. Overall, the instrument appears to be extremely well-suited as a measure of goal orientations among adults. Whether the current instrument generalizes to younger students is a topic for future research. Used as a placement measure, the Goals Inventory may help to identify students at risk for maladaptive behaviors in the classroom or workplace. Used diagnostically, it may clarify the type of beliefs and behaviors that contribute to low performance and low self-esteem.

\section{References}

Ames, C. (1992). Classrooms: Goals, structures, and student motivation. Journal of Educational Psychology, 84, 261-271.

Ames, C., \& Archer, J. (1988). Achievement in the classroom: Student learning strategies and motivational processes. Journal of Educational Psychology, 80, 260-267.

Blumenfeld, P. C. (1992). Classroom learning and motivation: Clarifying and expanding goal theory. Journal of Educational Psychology, 84, 272-281.

Diener, C. I., \& Dweck, C. S. (1978). An analysis of learned helplessness: Continuous changes in performance, strategy, and achievement cognitions after failure. Journal of Personality and Social Psychology, 36, 451-462.

Dweck, C. S. (1975). The role of expectations and attributions in the alleviation of learned helplessness. Journal of Personality and Social Psychology, 31, 674-685.

Dweck, C. S., \& Leggett, E. S. (1988). A social-cognitive approach to motivation and personality. Psychological Review, 95, 256-273.

Elliott, E. S., \& Dweck, C. S. (1988). An approach to motivation and achievement. Journal of Personality and Social Psychology, 54, 5-12. 
Meece, J. L., Blumenfeld, P. C., \& Hoyle, R. H. (1988). Students' goal orientations and cognitive engagement in classroom activities. Journal of Educational Psychology, 80, 514-523.

Miller, R. B., Behrens, J. T., Greene, B. A., \& Newman, D. (1993). Goals and perceived ability: Impact on student valuing, self-regulation, and persistence. Contemporary Educational Psychology, 18, 2-14.

Roedel, T. D., \& Schraw, G. (1993, April). The dimensionality of goal orientations in academic and social domains. Paper presented at the annual meeting of the American Educational Research Association. Atlanta, GA.

Sarason, I. G. (1984). Stress, anxiety, and cognitive interference: Reactions to tests. Journal of Personality and Social Psychology, 46(4), 929-938.

Schraw, G., \& Roedel, T. D. (1993, April). Beliefs about intelligence and academic goals. Paper presented at the annual meeting of the American Educational Research Association. Atlanta, GA.

Snyder, C. R., Harris, C., Anderson, J. R., Holleran, S. A., Irving, L. M., Sigmon, S. T., Yoshinobu, L., Gibb, J., Langelle, C., \& Harney, P. (1991). The will and the ways: Development and validation of an individual differences measure of hope. Journal of Personality and Social Psychology, 60(4), 570-585.

Weiner, B. (1985). An attributional theory of achievement motivation and emotion. Psychological Review, 92(4), 548-573. 